\title{
TDPBP Derivative Aiding Liquid-Phase Synthesis Strategy and ACE Inhibitory Structure-activity Relationship of Anti- SARS Octapeptide
}

Haidi Li, Jin Ren, Zixin Zhang, Junyou Li, Ninghui Chang and Chuanguang Qin*

Shaanxi Key Laboratory of Polymer Science \& Technology, OME Key Laboratory of Supernormal Material Physics \& Chemistry, Department of Chemistry, School of Chemistry and Chemical Engineering, Northwestern Polytechnical University, Xi'an, 710129, P. R. China.

Corresponding author E-mail: qinchg@nwpu.edu.cn

Abstract: The tri(4'-diphenylphosphonyloxylbenzoyl phenyl) phosphate (TDPBP) derivatives were designed and developed as C-terminal supports to aid the greener and highefficient liquid-phase peptide synthesis (LPPS) without the need of unrecyclable resin and chromatographic separation, whereby the anti-SARS octapeptide (2) (AVLQSGFR) was synthesized with TDPBP-OH support via Fmoc chemistry and support-aided precipitation (SAP) technology. Furthermore, the ACE inhibition and the inhibitory structure-activity relationship (SAR) between the synthetic C-terminal amidated derivate (1), anti-SARS octapeptide (2) and its alanine-scanning sequence analogues (3) to (9) were systematically studied by HPLC analysis and 3D-QSAR via molecular docking. 


\section{Introduction}

More and more attention from pharmaceutical scientists has been given to the development of peptide-based drugs. [1] Compared with small molecule drugs, peptide-based drugs display outstanding edges in affinity, specificity, and metabolic toxicity.[2] Therefore, the innovation of novel peptide-based new drugs or new strategies for peptide-based drug preparation is of considerable significance.[3]

To date, the raw materials of peptide-based drugs were mainly derived from expensive biological extraction technology or chemical pathway with the solid-phase peptide synthesis (SPPS) strategy.[4] For chemical synthesis, SPPS can significantly simplify the cumbersome synthetic processing of peptides. However, SPPS requires expensive and unrecyclable resin as necessary supports.[5] The peptide elongation process requires excessive use of amino acids to participate in the coupling due to the heterogeneous reaction. Besides, the resins attached peptide need a large number of solvents to wash for each step, which leads to an increase in process mass intensity (PMI: the ratio of the entire mass of all raw materials over the mass of target products).[6] Hence, it is challenging to implement large-scale and atomic economic chemical peptide synthesis and preparation.

For homogeneous phase reaction, the soluble polymer supports, such as PEG-modified anchors, [7] multi-attachment sites poly(norbornene)-derived anchor,[8] globular multi-sites anchor,[9] were developed as alternative soluble resin supports. Next, the soluble small molecule supports, such as the $\mathrm{OH}-\mathrm{Bz} \mid\left[\mathrm{Bzl}\left(\mathrm{OC}_{18}\right)_{3}\right]_{3}$ anchor,[10] the hydrophobic benzyl anchors,[11] the diphenylmethyl-derived anchors,[12] and the $\mathrm{N}$-phosphonyl and $\mathrm{BndppOH}$ protecting groups[13] were developed to achieve the equivalent conversion synthesis. 
Unwieldy to prepare the supports themselves were extremely adverse to the extensive longchain peptides synthesis. Also, it was hard to achieve greenness and atomic economy for peptide production.

Based on our group's recent studies regarding TFP, TBP, and DDK derivative supports for resin-free liquid-phase peptide synthesis (LPPS),[14] we further modified and improved the structure of the above supports. By introducing low-polarity and easily crystallizable group $\left(\mathrm{OPOPh}_{2}\right)$ that allows the entire supports molecule to form sizeable aromatic ring system, and effectively lessening the polarity of the molecular system, we successfully acquire a series of new tri (4'-diphenylphosphonyloxylbenzoylphenyl) phosphate (TDPBP) derivatives as greener peptide-synthesis supports (GPS). (Figure 1). The modified TDPBP supports can perform large-scale and atomic economic liquid-phase Fmoc strategy peptide synthesis in high yields, and effectively obviate the gelation phenomenon of peptide sequences rich in Phe, Val, and Ala residues during the peptide chain extension process.

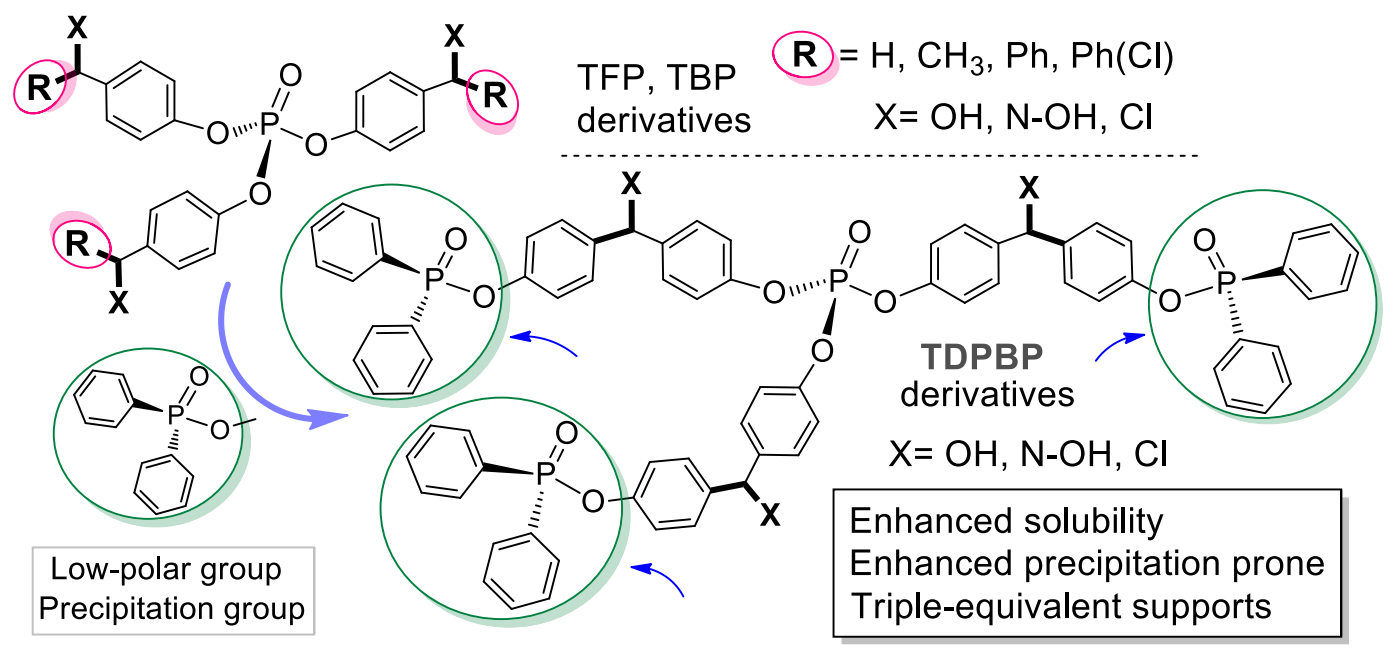

Figure 1. Structure modification of the TBP, TFP and DDK derivatives.

Severe coronavirus infections broke out worldwide in 2019 and 2003, which posed a grave threat to the safety of human life,[15] necessitating the development of effective 
peptide-based antiviral drugs against CovID-19 and SARS-CoV for future latent coronavirus reoccurrence. $[15,16]$ Meanwhile, the new strategies for peptide-based drugs preparation are also of great significance. The AVLQSGFR octapeptide has been reported to have manifest anti-SARS virus activity.[17] The molecular docking studies of the octapeptide to SARS-CoV $\mathrm{M}^{\text {pro }}$ based on the three-dimensional structure of the main proteinase in SARS coronavirus have indicated that the anti-SARS octapeptide was bound to the SARS proteinase through six hydrogen bonds, which will further provide a solid foundation for conducting peptidebased drug development against the global outbreak CovID-19 epidemic.[16]

Hence, the anti-SARS octapeptide (2) AVLQSGFR containing easily gelation amino acids (Ala, Val, Phe) was selected as the template peptide sequence to verify the superb applicability of the TDPBP derivative support, ensured by realizing a new resin-free, atomic economic, large-scale and green liquid-phase synthesis strategy of anti-SARS octapeptide.

Next, we systematically plumbed the ACE inhibitory activity and the structure-activity relationship (SAR) of anti-SARS octapeptide (2) and its alanine-scanning sequence analogues. Furthermore, The 3D-QSAR of C-terminal amidated derivate (1), anti-SARS octapeptide (2) and its alanine-scanning sequence analogues were investigated as well via molecular docking, and found the potent ACE inhibitory activity of octapeptide AVLQSGFR, which proves that the octapeptide (2) is a peptide-based molecule with multiple physiological functions such as inhibition against not only SARS coronavirus main proteinase, but also ACE. This finding may lay a foundation for further understanding the molecular mechanism of how to prevent SARS COV-2 from infecting the human body through its receptor ACE. 


\section{Results and discussion}

Design and synthesis of TDPBP derivative supports. A high-yield and convenient synthetic route for TDPBP derivatives was demonstrated in Scheme 1. The starting material 4,4'-dihydroxybenzophenone was treated with one equivalent $\mathrm{Ph}_{2} \mathrm{POCl}$ to afford the intermediate product 1 in $85 \%$ yield. Next, three equivalent 1 was processed with $\mathrm{POCl}_{3}$ to obtain the TDPBP intermediate 2 in $97 \%$ yield. Then, 2 was reduced by $\mathrm{NaBH}_{4}$ to attain the TDPBP-OH support 3 in $98 \%$ yield. Afterwards, 2 continued to react with $\mathrm{SOCl}_{2}$ to derive TDPBP-Cl support 5 in $99 \%$ yield. Lastly, 2 reacted with $\mathrm{NH}_{2} \mathrm{OH} \cdot \mathrm{HCl}$, affording the TDPBP=N-OH support 4 in $82 \%$ yield. The TDPBP supports, with high solubility in the medium such as DCM and EA, could be precipitated in EA/PE solvents.

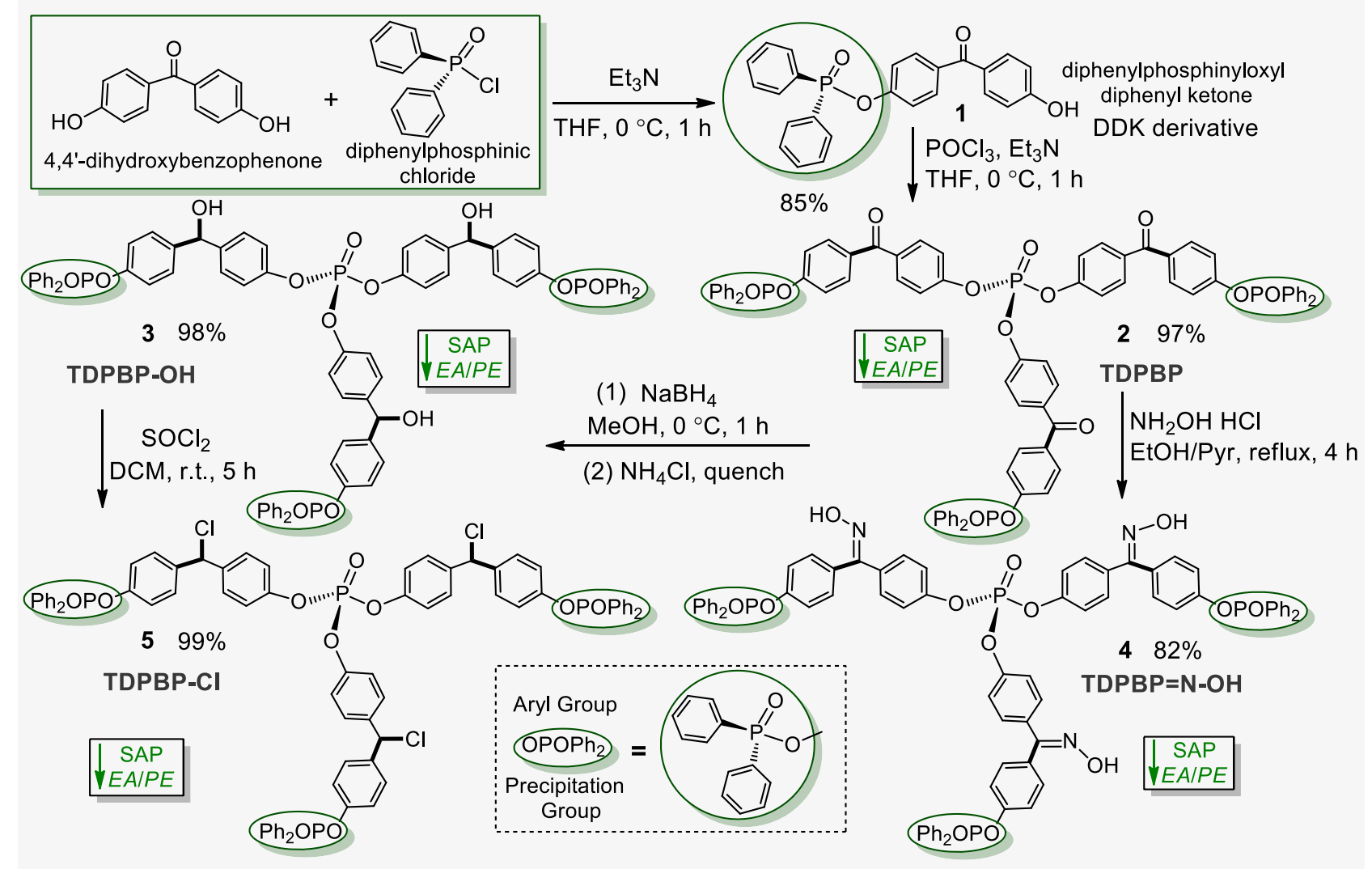

Scheme 1. Synthesis of TDPBP Derivatives as Greener Peptide-synthesis Supports (GPS). 
Synthesis of anti-SARS octapeptide. As we expected, TDPBP derivatives still exhibit specific acid-base stability, that was, the coupling product of TDPBP-OH with amino acids was stable in base (25\% DEA in $\mathrm{MeCN})$ condition, while the coupling product of TDPBP $=\mathrm{N}-\mathrm{OH}$ with amino acids was relatively stable in acid $(25 \%$ TFA in DCM) condition. Therefore, we selected the TDPBP-OH support to conduct the synthesis of anti-SARS octapeptide AVLQSGFR by Fmoc strategy. (Scheme 2)

First, three equiv Fmoc-Arg(Pbf)-OH with more substantial steric hindrance was loaded on the TDPBP-OH support via the EDC.HCI/DMAP coupling system. During the coupling process, there was no decrease in yield courtesy of the space crowding, attested by $97 \%$ yield of the coupling product $[\mathrm{Fmoc}-\mathrm{Arg}(\mathrm{Pbf})-\mathrm{O}]_{3}-\mathrm{TDPBP}$ in this step, while the coupling time was extended to $3 \mathrm{~h}$. The de-Fmoc process was carried out under the base condition (DEA/MeCN, $v / v 1: 3$ ), and the de-Fmoc, with the yield of $99 \%$, was directly coupled with the following amino acid Fmoc-Phe-OH without further purification to derive the [Fmoc-Phe-Arg(Pbf)-O]3-TDPBP in $98 \%$ yield via the $\mathrm{EDC} \cdot \mathrm{HCl} / \mathrm{HOBt} / \mathrm{DIEA}$ coupling system. For the next step, we continued extending the peptide chain to afford the TDPBP-OH attached octapeptide intermediate product [Fmoc-Ala-Val-Leu-GIn(Trt)-Ser(tBu)-Gly-Phe-Arg(Pbf)-O]3-TDPBP with $61 \%$ total yield. It is worth noting that when the peptide chain was extended to the 7 th amino acid, Fmoc-Val-OH, a decrease in the solubility of the solution system was invoked, and the reaction solvent changed to chloroform, the precipitation reagent changing to $\mathrm{EA} / \mathrm{MeCN}$ or EA/MeOH system. Nevertheless, the TDPBP-OH attached octapeptide products were obtained still in high yields. 
Next, the shearing reagents system TFA/Tis/ $\mathrm{H}_{2} \mathrm{O}(v / v / v, 95: 2.5: 2.5)$, was used to cleave the octapeptide chain from the TDPDP-OH support, the side-chain Pbf, Trt and $t \mathrm{Bu}$ protecting groups were removed at the same time. In this way, we successfully afford the target anti-SARS octapeptide (2) AVLQSGFR in 95\% yield.

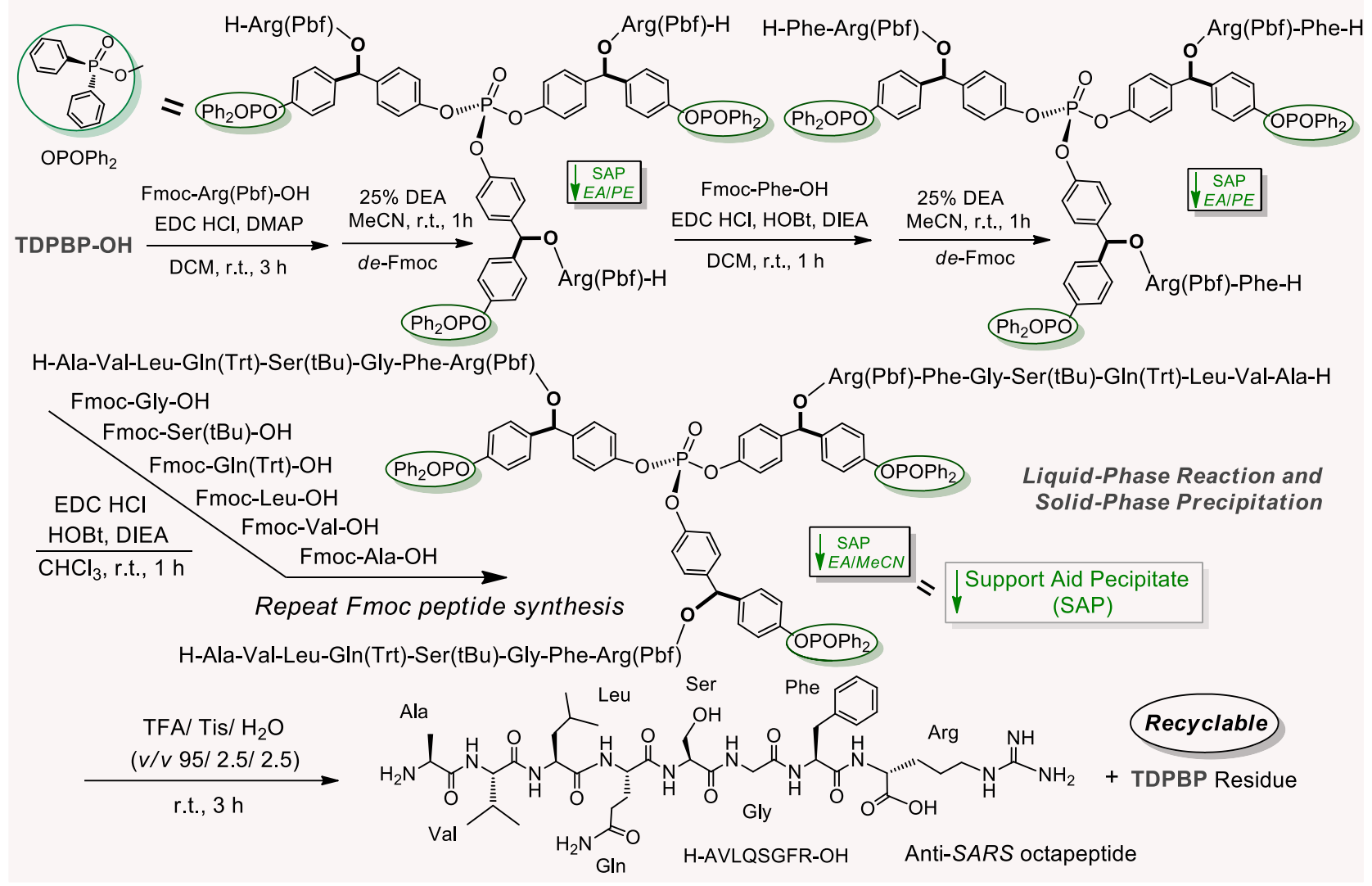

Scheme 2. The General Synthetic Route of Anti-SARS octapeptide (2) AVLQSGFR.

Structural stability of anti-SARS octapeptide (2). The preliminary molecular structural stability analysis for the minimum energy and the number of intramolecular hydrogen bonds of the anti-SARS octapeptide (2) indicate that the steric energy of anti-SARS octapeptide (2) was -39.895 , with six hydrogen bonds in the molecule, relatively stabilizing the molecular structure of anti-SARS octapeptide (2). Presented as a linear peptide with many bends in the main chain, the bend is not smooth at Phe-2, Leu-6, Val-7. (see Figure S9 in the SI) 
In vitro ACE inhibitory evaluation. Herein, the HPLC analysis method was used to evaluate the in vitro ACE inhibition of anti-SARS octapeptide (2) H-AVLQGFR-OH and its amide octapeptide (1) H-AVLQGFR-NH2. The size of inhibitory activity was calculated by the detection of the content of generated Hip (Hippuric acid: the decomposition product of Angi simulants Hippury-L-Histidyl-L-Leucine $(\mathrm{HHL}))$ after adding the control group captopril, antiSARS octapeptide and amide octapeptide. The results show that the inhibition rate of antiSARS amide octapeptide (1) varies significantly within the test concentration range. AntiSARS octapeptide (2) and the positive control captopril have significant inhibitory effects on ACE. The IC50 of anti-SARS octapeptides (2) and amide octapeptide (1) were $34 \mu \mathrm{mol} \cdot \mathrm{L}^{-1}$ and $240 \mu \mathrm{mol} \cdot \mathrm{L}^{-1}$, respectively, which indicates that the C-terminal amidation of octapeptide has reduced the ACE inhibitory activity.[18] (See Figure S5 in the SI)

Structure-activity relationship (SAR) studies of ACE inhibitory peptides[19] illuminate that the interaction of different peptide substrates with ACE was significantly affected by the Cterminal tripeptide sequence. ACE tends to bind with C-terminal hydrophobic amino acid, Nterminal aliphatic amino acid or competitive inhibitor, and the positive charge of the guanidine group on the C-terminal Arg can increase the ACE inhibitory activity of peptides. The hydrophilic-hydrophobicity of peptides is also a pivotal factor that affects ACE inhibitory.

The C-terminal of the H-AVLQSGFR-OH sequence contains aromatic amino acids Phe (F) and $\operatorname{Arg}(R)$ with guanidine group, and the N-terminal AVL of the chain are aliphatic amino acids with excellent hydrophobicity. These were consistent with the principle of the structureactivity relationship of ACE inhibitory peptides, which is the leading reason for the prominence of ACE inhibitory activity of the sequence. 
In vitro gastrointestinal protease tolerance study. The gastrointestinal protease tolerance of anti-SARS octapeptide (2) was studied by simulating the gastrointestinal tract in vitro. After the digestion of anti-SARS octapeptide (2) by pepsin for $3 \mathrm{~h}$, the difference of ACE inhibitory was not significant, compared with the undigested control group. However, after the digestion of anti-SARS octapeptide (2) by trypsin for $3 \mathrm{~h}$, the ACE inhibitory activity was significantly different from that of the control group (Figure 2A and 2B).

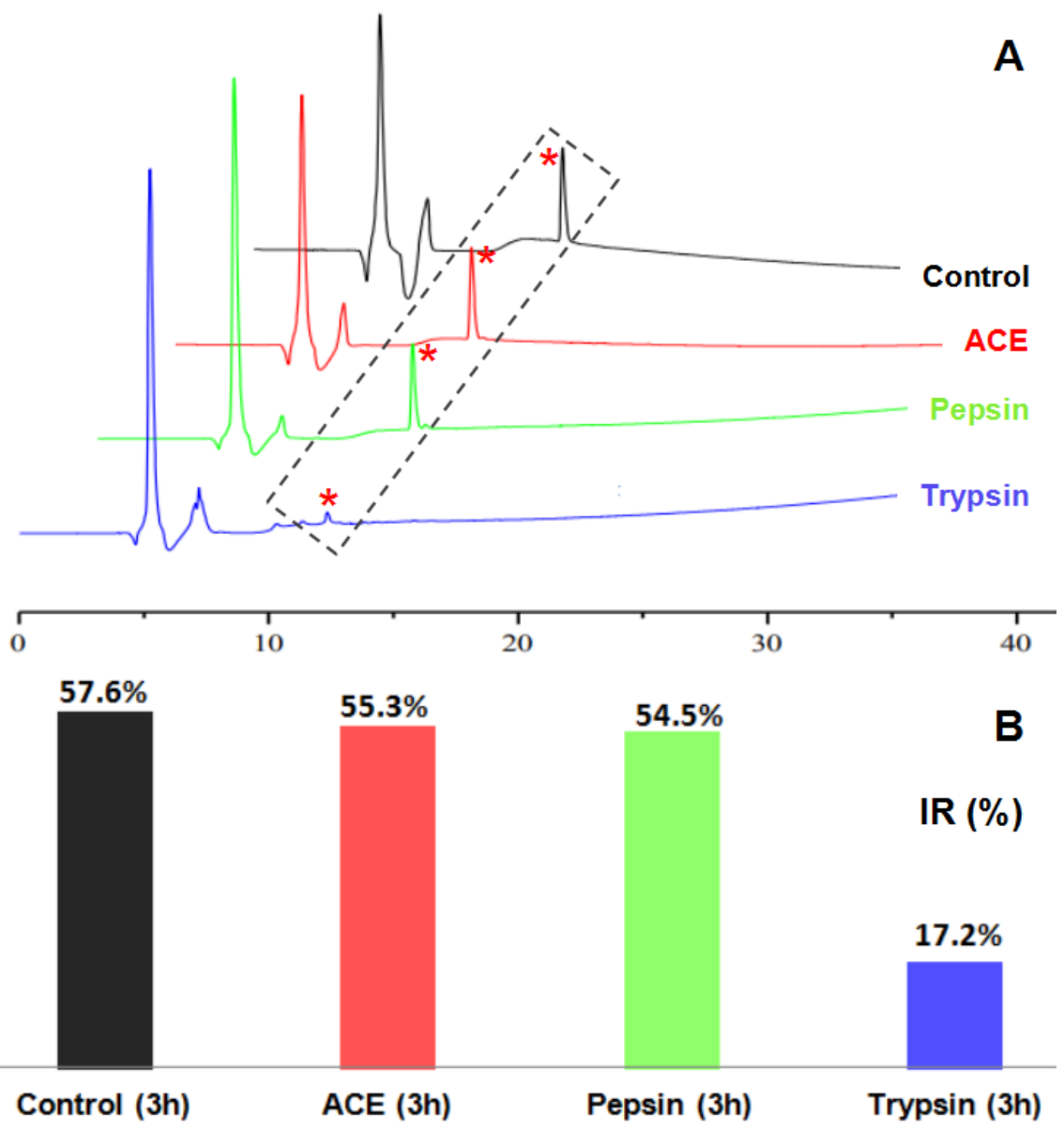

Figure 2. A: HPLC analysis of octapeptide (2) before and after ACE treatment and in vitro digestive. Control group; ACE treat for $3 \mathrm{~h}$ group; Pepsin digestion for $3 \mathrm{~h}$ group; Pepsin digestion for $3 \mathrm{~h}$ and further trypsin digestion $3 \mathrm{~h}$ group. B: The ACE inhibitory rate of octapeptide (2) after gastrointestinal enzyme digestion. 
The anti-SARS octapeptide (2) can tolerate the pepsin effect in the gastrointestinal tract, and the ACE inhibitory remained almost unchanged before and after digestion. However, its tolerance of the trypsin effect lacks, primarily in that octapeptide (2) sequence contains arginine $(R)$ residue, the Asp in the active centre of trypsin is conducive to binding the positively charged Arg. Therefore, the trypsin can hydrolyze the Arg formed peptide, suggesting that anti-SARS octapeptide (2) cannot be directly absorbed and utilized by oral administration and then participate in the hypotensive process with high activity.

Temperature and ACE effect on the stability of anti-SARS octapeptide (2). Anti-SARS octapeptide (2) was treated under different temperatures, $20^{\circ} \mathrm{C}, 40{ }^{\circ} \mathrm{C}, 60^{\circ} \mathrm{C}, 80^{\circ} \mathrm{C}$, and $100{ }^{\circ} \mathrm{C}$ separately for $2 \mathrm{~h}$, followed by the test of inhibited ACE activity. The results portrait the subtle change of ACE inhibitory of anti-SARS octapeptide (2) with different temperatures, boasting excellent thermal stability within $100^{\circ} \mathrm{C}$. (See Figure $\mathbf{S} 7$ in the SI)

Then, we researched the effect of ACE itself on the activity of octapeptide (2). Before and after treating octapeptide (2) with ACE, the inhibition rate changed slightly, the difference in inhibitory activity was not significant, which indicates that octapeptide was a real inhibitor and will not be affected by ACE itself while maintaining the original activity of anti-SARS octapeptide (2). (See Figure S8 in the SI)

Inhibition mechanism study of anti-SARS octapeptide (2). ACE inhibitory peptides play a role in lowering blood pressure by inhibiting ACE activity in vivo. The inhibitory effect on ACE was divided into three types: [20] the competitive inhibition type; the non-competitive inhibition type; the mixed inhibition type. So, the inhibition kinetics was applied to study the inhibition mechanism of anti-SARS octapeptide (2). According to the amount of Hip produced 
(decomposed by HHL substrate after treating with ACE with different concentrations) per minute, the reaction speeds $V_{0}$ of octapeptide (2) with different concentration were calculated pursuant to the Lineweaver-Burk Mie equation as follow (Equation 1). Based on the reciprocal of the reaction rate $\left(1 / V_{0}\right)$ and substrate concentration $(1 /[S])$, we derived the Lineweaver-Burk line (Figure 3), the slope of the line being $K_{m} V_{\max }$, and the intercept being $1 / V_{\max }$. The type of inhibition of peptides is contingent on $K_{m}$ and $V_{\max }$. In general, if $V_{\max }$ changes significantly, while $K_{m}$ maintains a specific value, the type of inhibition of ACE was non-competitive, otherwise the opposite.

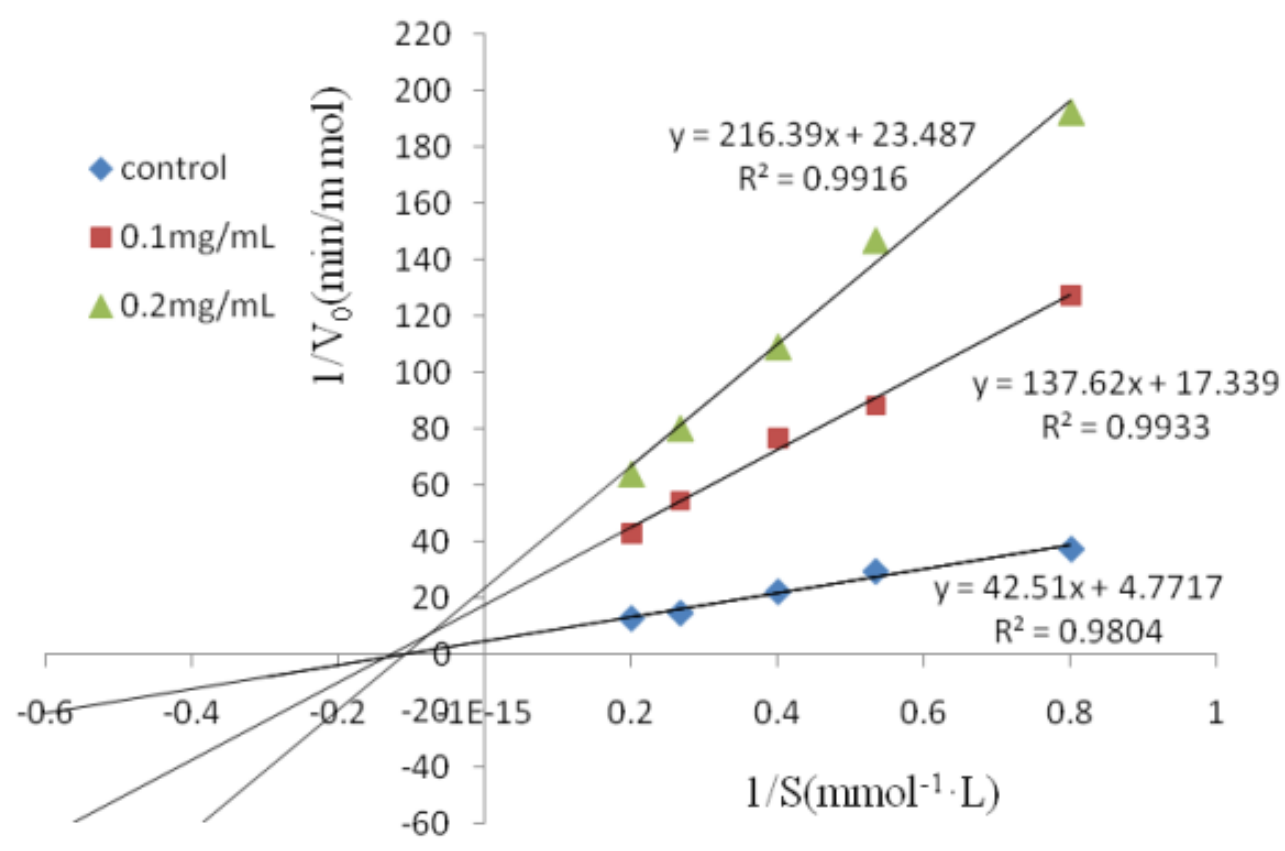

Figure 3. Lineweaver-Burk plot ACE activity in the presence of octapeptide (2) at different concentration.

According to the linear equations in Figure 3, $V_{\max }$ of the control group, octapeptide (2) $\left(0.1 \mathrm{mg} \cdot \mathrm{mL}^{-1}\right)$ group, and octapeptide (2) $\left(0.2 \mathrm{mg} \cdot \mathrm{mL}^{-1}\right)$ group were 42.58, 57.67, 209.57 $\mu \mathrm{mol} / \mathrm{L}$ min, respectively, $K_{m}$ were $9.22,7.94,8.91 \mathrm{mmol} \cdot \mathrm{L}^{-1}$, respectively, which proves that 
$V_{\max }$ changes tremendously, while $K_{m}$ only changes slightly. The result indicates that the type of ACE inhibits was non-competitive.

$$
\frac{1}{V}=\frac{K_{m}}{[S]} \cdot \frac{1}{V_{\max }}+\frac{1}{V_{\max }}
$$

\section{ACE inhibitory structure-activity relationship of anti-SARS octapeptide and its Ala-}

scanning analogues. The ACE inhibitory activities of the octapeptide analogues (3) to (9), which were the alanine scanning sequences of anti-SARS octapeptide (2), were evaluated. The results showed the ACE inhibition rates of octapeptides (2) to (9) with different concentrations. The results of Figure 4 and Figure S10 in the SI reveals that the inhibition rates of octapeptides (3) to (6) at various concentrations on ACE were similar to that of antiSARS octapeptide (2), while the inhibition rates of (7), (8), and (9) on ACE were significantly lower than that of octapeptide (2). That meant, the ACE inhibitory activity obviously declined after the GIn (Q), Leu (L) and Val (V) in the octapeptide sequence H-AVLQSGFR-OH was replaced by Ala $(A)$, respectively. However, the ACE inhibitory activity changed little after the C-terminal arginine (R), Phe (F), Gly (G) and Ser (S) was replaced by Ala (A), respectively. The results indicats that $V, L$, and $Q$ residues in the anti-SARS octapeptide (2) sequence were indeed important for ACE inhibition. The structure-activity relationship of ACE inhibitory peptides suggests that ACE tends to bind with a substrate that contains a hydrophobic amino acid at the C-terminus (F) and an aliphatic amino acid at the $\mathrm{N}$-terminus. The positive charge of the guanidine group can increase ACE inhibitory activity.[19] However, in this experiment, it was proved that the $\mathrm{C}$-terminal hydrophobic amino acid $(\mathrm{F})$ and guanidine-containing Arg (R) exert little effect on ACE inhibitory activity of anti-SARS octapeptide (2). 


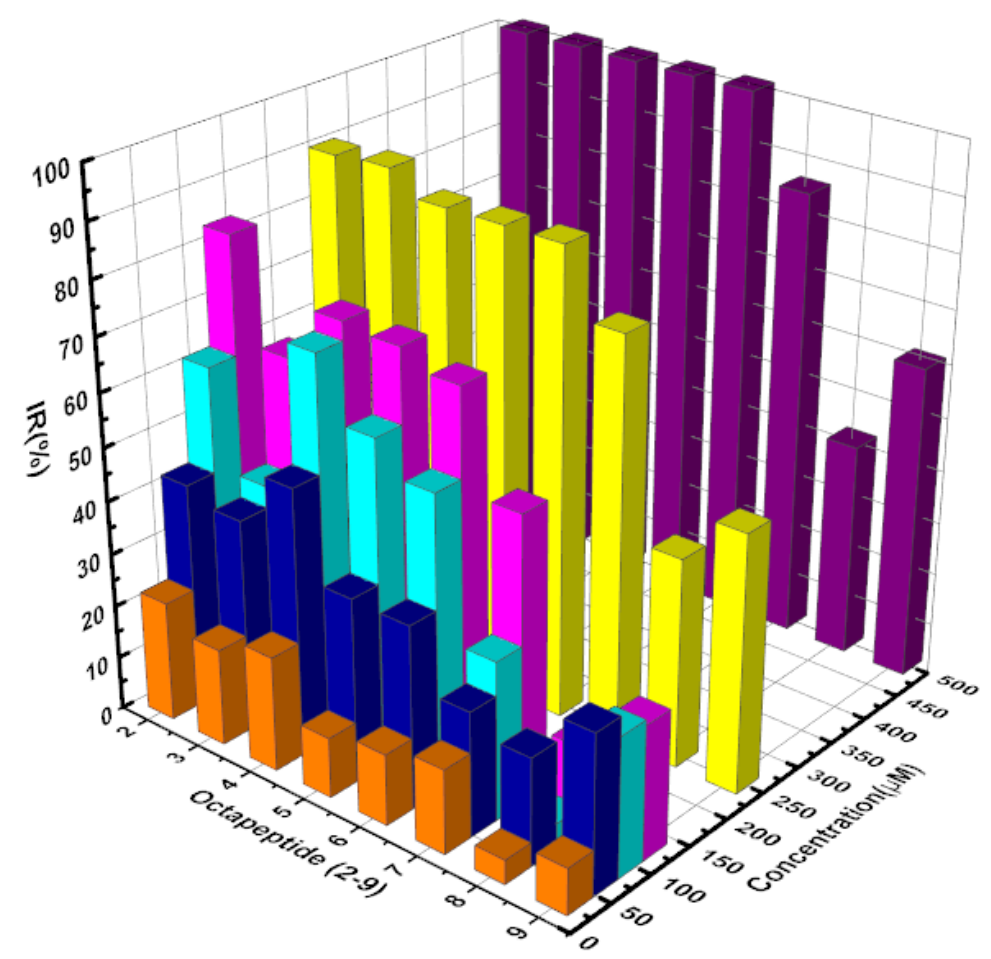

Figure 4. The inhibitory rate of octapeptide (2) and its Ala-substituted analogues (3) to (9) at their different concentrations against ACE.

However, the octapeptide (2), encompassing $\operatorname{Arg}(R)$, cannot tolerate the digestion of trypsin, making the oral administration impossible. The results show that when $\mathrm{R}$ changed into A, ACE inhibitory activity did not change apparently, meaning that $\mathrm{R}$ bears little effect. Consequently, it is worth considering to substitute $\mathrm{R}$ with other amino acids to develop a peptide sequence that holds better ACE inhibitory activity and can simultaneously tolerate the gastrointestinal protease digestion for the screening of oral antihypertensive drugs.

In addition, Gan et al.[17b] obtained the anti-SARS octapeptide (2) via solid-phase synthesis, and conducted relevant experiments on anti-SARS coronavirus' activity and cytotoxicity. The comprehensive study suggests that this octapeptide (2) can significantly inhibit the replication of SARS coronavirus and simultaneously has ACE inhibitory activity, and was attested by no signs of cytotoxicity in the detected cells within the scope of 
concentration. However, the question is why this sequence has these two types of activitiy? It is admitted that only the angiotensin conversion enzyme 2 (ACE2), discovered in 2000, is homologous to ACE. ACE2 is also involved in renin-angiotensin system (RAS), and has been determined as a functional receptor for CovID-19 and SARS coronavirus.[21, 22, 23] We already know that during the infection process, the combination between the $S$ protein of SARS coronavirus and intracellular ACE2 occurs in the first step,[24] whereas the problem in relation to the process still wants further explanation.

\section{Quantitative structure-activity relationship (QSAR) study of anti-SARS octapeptide}

(2) and its analogues for ACE inhibiting. Molecular docking technology is constantly employed for virtual screening of bioactive molecules and the rational design of drug candidates. The molecular mechanisms of interactions between ACE and ACE inhibitory peptides have many potentially favorable consequences for further designing and synthesizing their derivatives.[25] To explore the quantitative structure-activity relationship (QSAR) and binding mechanism of anti-SARS octapeptide (2) (ligand 2, H-AVLQSGFR-OH) and its analogues against ACE, the computation of molecular docking was made. The most stabilized pose of the anti-SARS octapeptide (2) (ligand 2) bond with ACE1 (PDB: 1O8A) was obtained, and their $3 \mathrm{D}$ and $2 \mathrm{D}$ structures were exhibited in Figure $5 \mathrm{~A}$ and $5 \mathrm{~B}$, respectively. The inhibitor combined with the residues of ACE through the main interaction forces of hydrogen bonds, Van der Waals, hydrophobic and electrostatic force. The hydrogen bonds interaction force played the leading role. The molecular docking of anti-SARS octapeptide (2) (ligand 2) on the ACE1 binding site revealed that anti-SARS octapeptide (2) was encompassed by a hydrophilic pocket which formed by the hydrogen bonds of 
hydrophilic interactions. The anti-SARS octapeptide (2) makes contact via the hydrogen bond interactions with Asn70, Glu162, Thr282, Cys352, Glu384, His387, Glu411 of ACE1, as well the electrostatic interactions with Glu143 and zinc cation as a metal-acceptor of ACE1 (Figure 5B). Also, the ligand 2 makes contact via the Van der Waals interactions with Asn66, Thr166, Gln281, Asn277, Trp279, Val351, Trp357, Lys368, Gln369, Cys370, Thr371, Glu376, Phe391, His410, Glu411, Lys454, Phe457, Phe512, Ser516, Val518, Tyr520, Arg522 of ACE1, as well the hydrophobic interactions such as alkyl interaction with Ala356, Val379, Val380, $\pi-\pi$ stacking force with His387, $\pi-\sigma$ interaction with His383 and unfavorable donordonor interaction with Ala354 of ACE (Figure 5C).
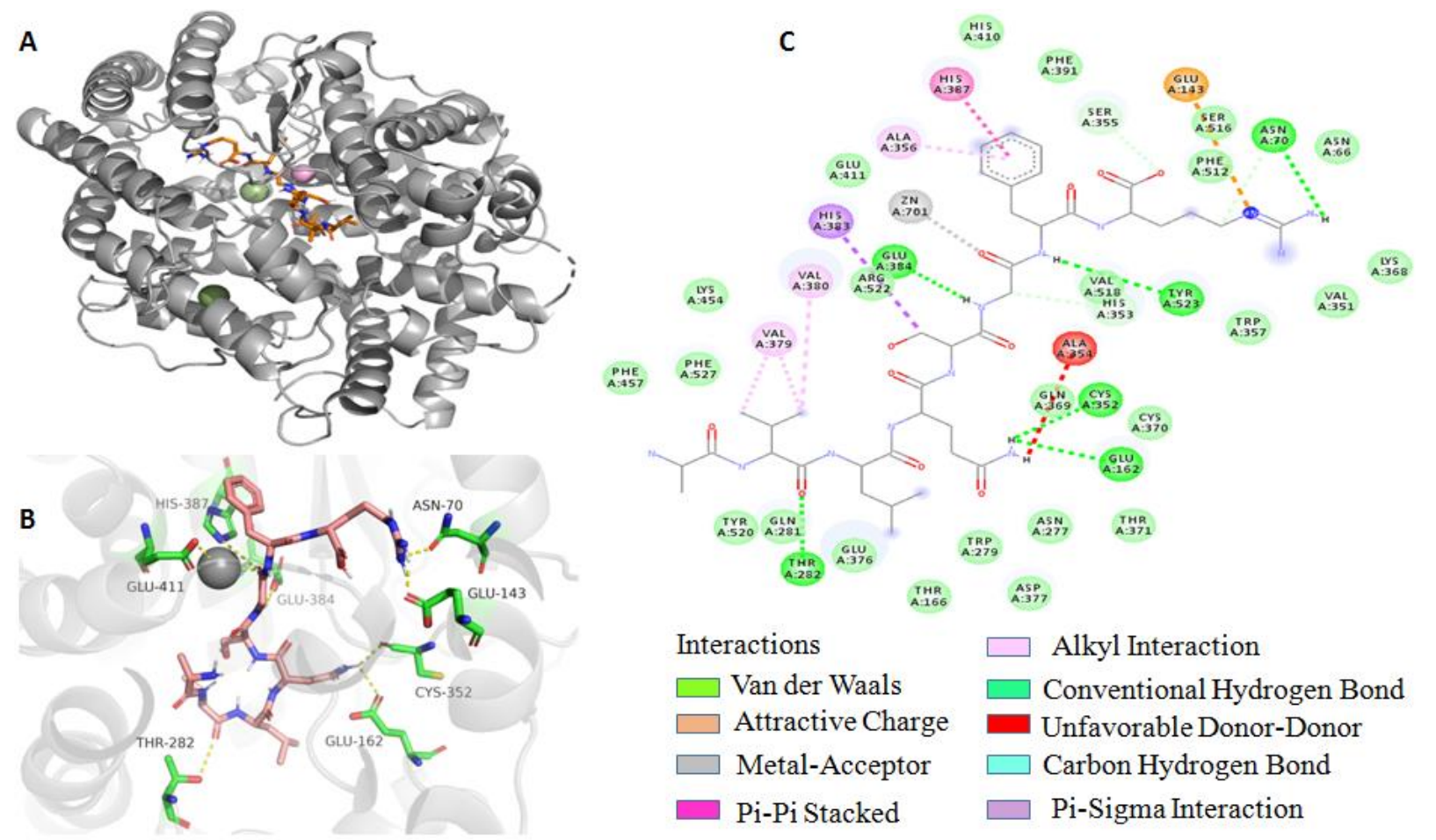

Figure 5. The best ranked docking pose of anti-SARS peptide 2 (AVLQSGFR-OH) binding with ACE1 (PDB: 1O8A). A: Full view of ACE1(PDB: 1O8A, Dark gray )-ligand2 (AVLQSGFR-OH, Dark orange) complex; B: Binding mode of ACE1 (Light grey and green) with Ligand 2 (H-AVLQSGFR-OH, Dark orange); C: All kinds of interactions between ACE1 
residues and atoms or atomic groups on Ligand 2.

Table 1. ACE binding energy by docking and measured ACE inhibitory activaties of antiSARS octapeptide and its analogues.

\begin{tabular}{cccccc}
\hline \multirow{2}{*}{ entry } & \multirow{2}{*}{ Ligands } & \multirow{2}{*}{$\begin{array}{c}\text { Octapeptide } \\
\text { Sequence }\end{array}$} & \multicolumn{2}{c}{$\begin{array}{c}\text { Binding Energy } \\
(\mathrm{kcal} / \mathrm{mol})\end{array}$} & \multirow{2}{*}{$\begin{array}{c}\text { ACE Inhibition } \\
\text { IC50 }(\mu \mathrm{M})\end{array}$} \\
\cline { 4 - 5 } & & ACE1 & ACE2 & \\
\cline { 4 - 5 } 1 & Ligand1 & H-AVLQSGFR-NH 2 & -9.5 & -9.3 & 220.7 \\
2 & Ligand2 & H-AVLQSGFR-OH & -9.7 & -10.2 & 75.3 \\
3 & Ligand3 & H-AVLQSGFA-OH & -9.2 & -9.5 & 100.5 \\
4 & Ligand4 & H-AVLQSGAR-OH & -9.2 & -9.0 & 62.5 \\
5 & Ligand5 & H-AVLQSAFR-OH & -9.5 & -9.4 & 82.3 \\
6 & Ligand6 & H-AVLQAGFR-OH & -9.5 & -10.1 & 86.4 \\
7 & Ligand7 & H-AVLASGFR-OH & -9.1 & -9.8 & 131.3 \\
8 & Ligand8 & H-AVAQSGFR-OH & -9.5 & -9.4 & $>500$ \\
9 & Ligand9 & H-AALQSGFR-OH & -9.2 & -8.9 & 316.5
\end{tabular}

The interaction energies of anti-SARS octapeptide (2) (H-AVLQSGFR-OH) and its analogues binding with ACEs (both types 1 and 2) were summarized in Table 1. The results by molecular docking indicated that the complexes of ligand 2 (H-AVLQSGFR-OH) with ACE1 and ACE2 were the most stable ones with the interaction energy of -9.7 and -10.2 $\mathrm{kcal} / \mathrm{mol}$ respectively among those of its analogues. The binding energy of ligand $1(\mathrm{H}-$ AVLQSGFR-NH $\mathrm{N}_{2}$ ) in which the C-terminal hydroxyl group was substituted by the amino group decreased to $-9.5 \mathrm{kcal} / \mathrm{mol}$ with ACE1 and $-9.3 \mathrm{kcal} / \mathrm{mol}$ with ACE2. The binding energies of the analogues (ligand 3-9), which sequences changed by alanine-scanning one by one, went down to the range of -9.1 to $-9.5 \mathrm{kcal} / \mathrm{mol}$ with $\mathrm{ACE} 1$, and -8.9 to $10.1 \mathrm{kcal} / \mathrm{mol}$ with $\mathrm{ACE} 2$. It suggested that the residues of four amino acids, such as Arg, Phe, Gln, and Val in the anti- 
SARS octapeptide sequence (ligand 2), significantly contributed to the combinative stabilization. (Figure S12 in the SI)

On the other hand, the inhibitory activities as $\mathrm{IC}_{50}$ of anti-SARS octapeptide (2) (ligand 2) and its analogues against ACE measured by the experiment were listed in Table 1. Except for that of ligand 1 and 8 , most of the measured values agree with the simulated theoretical values by molecular docking. It suggested that the $\mathrm{C}$-terminal hydroxyl group and the residue of Leu in the sequence of anti-SARS octapeptide (ligand 2) play a crucial role and have a strong effect on the actual $I_{50}$ of anti-SARS octapeptide (ligand 2) inhibiting ACE. In summary, anti-SARS octapeptide (2) (ligand 2) is indeed an excellent ACEs (both types 1 and 2) inhibitor. No matter theoretically or experimentally, the sequence AVLQSGFR compared with its analogues is the optimal binding ligand to ACEs (both types 1 and 2).

\section{Conclusion}

In this work, we utilized the designed TDPBP derivatives as greener support to synthesize the anti-SARS octapeptide template AVLQSGFR. A new simplified liquid-phase strategy was successfully established and demonstrated via Fmoc chemistry and support-aided precipitation for the implementation of large-scale, atom economic synthesis and preparation of biologically active peptides, without the use of resin and chromatographic separation. Additionally, we systematically studied the ACE inhibitory of anti-SARS octapeptide and the ACE inhibitory structure-activity relationship (SAR) of anti-SARS octapeptide and its analogues, and found the critical amino acids sequence for ACE inhibition. This provides a solid foundation for the design and synthesis of peptides to develop bi- or multi-functional therapeutic drugs for antihypertension and anti-SARS CoV in the future. 


\section{Acknowledgement}

This work was supported by the National Natural Science Foundation of China (21572180, 21602176, 21602174), the Intergovernmental Science and Technology Cooperation and Exchange Program between China and Romania (43-24-20180510), the National College Students' Innovation and Entrepreneurship Training Program of China (14GZ1608), the Basic Research Plan of Natural Science in Shaanxi Province of China (2012JZ2002), the Academic Funding of Northwestern Polytechnical University (NPU, 17GH0402, W212002). Thanks to Mr. Cheng Chen in Prof. Kewu Yang's lab at the Department of Chemistry, Northwest University, and Dr. Huimeng Lu in School of Life Sciences, Northwestern Polytechnical University for their contributes to molecular docking. We gratefully acknowledge the Analytical \& Testing Center of Northwestern Polytechnical University for the NMR analysis.

\section{Competing financial interests}

The authors declare no competing financial interests.

\section{Additional information}

Supplementary information and chemical compound linking are available in the online version of the paper.

\section{References}

1. (a) Nielsen, D. S., Shepherd, N. E., Xu,W.; Lucke, A. J., Stoermer, M. J., Fairlie, D. P. Orally absorbed cyclic peptides. Chem. Rev. 117, 8094-8128 (2017). (b) Dougherty, P. G., Sahni, A., Pei, D. Understanding cell penetration of cyclic peptides. Chem. Rev. 119, 
10241-10287 (2019). (c) Malonis, R. J., Lai, J. R., Vergnolle, O. Peptide-based vaccines: current progress and future challenges. Chem. Rev. 120, 3210-3229 (2020). (d) Jones, L. H., Recent advances in the molecular design of synthetic vaccines. Nat. Chem. 7, 952-960 (2015).

2. (a) Kong, X. D., Moriya, J., Carle, V., Pojer, F., Abriata, L. A., Deyle, K., Heinis. C., De novo development of proteolytically resistant therapeutic peptides for oral administration. Nat. Biomed. Eng. 4, 560-571 (2020). (b) Kale, S. S., Villequey, C., Kong, X. D., Zorzi, A.; Deyle, K., Heinis, C., Cyclization of peptides with two chemical bridges affords large scaffold diversities. Nat. Chem. 10, 715-723 (2018). (c) Fleming, K. A., Freeman, K. T., Ericson, M. D., Haskell-Luevano, C., Synergistic multiresidue substitutions of a macrocyclic c[Pro-Arg-Phe-Phe-Asn-Ala-Phe-dPro] agouti-related protein (AGRP) scaffold yield potent and $>600$-fold MC4R versus MC3R selective melanocortin receptor antagonists. J. Med. Chem. 61, 7729-7740 (2018).

(3) (a) Hamley, I. W., Small bioactive peptides for biomaterials design and therapeutics. Chem. Rev. 117, 14015-14041 (2017). (b) Sarojini, V., Cameron, A. J., Varnava, K. G., Denny, W. A., Sanjayan, G., Cyclic tetrapeptides from nature and design: a review of synthetic methodologies, structure, and function. Chem. Rev. 119, 10318-10359 (2019). (c) Bozhüyük, K. A. J., Linck, A., Andreas, T., Kranz, Janik., Wesche, Frank., Nowak, S., Fleischhacker, F., Shi, Y. N., Grün, P., Bode, H. B., Modification and de novo design of non-ribosomal peptide synthetases using specific assembly points within condensation domains. Nat. Chem. 11, 653-661 (2019). (d) Suzuki, R., Brown, G. A., Christopher, J. A., Scully, C. C. G., Congreve, M., Recent developments in therapeutic peptides for the 
glucagon-like peptide 1 and 2 receptors. J. Med. Chem. 63, 905-927 (2020).

(4) Merrifield, R. B., Solid phase peptide synthesis. I. the synthesis of tetrapeptide. J. Am. Chem. Soc. 85, 2149-2154 (1963).

(5) (a) Jad, Y. E., Kumar, A., El-Faham, A., De la Torre, B. G., Albericio, F., Green Transformation of solid-phase peptide synthesis. ACS Sustainable Chem. Eng. 7, 3671-3683 (2019). (b) Al Musaimi, O., De la Torre, B. G., Albericio, F., Greening Fmoc/tBu solid-phase peptide synthesis. Green Chem. 22, 996-1018 (2020).

(6) Isidro-Llobet, A., Kenworthy, M. N., Mukherjee, S., Kopach, M. E., Wegner, K., Gallou, F., Smith, A. G., Roschangar, F. Sustainability challenges in peptide synthesis and purification: from R\&D to production. J. Org. Chem. 84, 4615-4628 (2019).

(7) (a) Pillai, V. N. R., Mutter, M., Bayer, E., Gatfield, I., New, easily removable poly (ethylene glycol) supports for the liquid-phase method of peptide synthesis. J. Org. Chem. 45, 5364-5370 (1980). (b) Fischer, P. M., Zheleva, D. I., Liquid-phase peptide synthesis on polyethylene glycol (PEG) supports using strategies based on the 9-fluorenyl methoxycarbonyl amino protecting group: application of PEGylated peptides in biochemical assays. J. Pept. Sci. 8, 529-542 (2002).

(8) Naganna, N., Madhavan, N., Soluble non-cross-linked poly (norbornene) supports for peptide synthesis with minimal reagents. J. Org. Chem. 2014, 79, 11549-11557. (b) Naganna, N., Madhavan, N., Soluble and reusable poly(norbornene) supports with high loading capacities for peptide synthesis. Org. Lett. 15, 5870-5873 (2013).

(9) (a) Castro, V., Noti, C., Chen, W. Q., Cristau, M., Livignston, A., Rodríguez, H., Albericio, F., Novel globular polymeric supports for membrane-enhanced peptide synthesis. 
Macromolecules. 50, 1626-1634 (2017). (b) So, S., Peeva, L. G., Tate, E. W., Leatherbarrow, R. J., Livingston, A. G., Membrane enhanced peptide synthesis. Chem. Commun. 46, 2808-2810 (2010).

(10) Tamiaki, H., Obata, T., Azefu, Y., Toma, K., A novel protecting group for constructing combinatorial peptide libraries. Bull. Chem. Soc. Jpn. 74, 733-738 (2001).

(11) (a) Okada, Y., Wakamatsu, H., Sugai, M., Kauppinen, E. I., Chiba, K., Acid-triggered colorimetric hydrophobic benzyl alcohols for soluble tag-assisted liquid-phase synthesis. Org. Lett. 17, 4264-4267 (2015). (b) Fujita, Y., Fujita, S., Okada, Y., Chiba, K., Soluble tagassisted peptide head-to-tail cyclization: Total synthesis of mahafacyclin B. Org. Lett. 15, 1155-1157 (2013). (c) Okada, Y., Suzuki, H., Nakae, T., Fujita, S., Abe, H., Nagano, K., Yamada, T., Ebata, N., Kim, S., Chiba, K., Tag-assisted liquid-phase peptide synthesis using hydrophobic benzyl alcohols as supports. J. Org. Chem. 78, 320-327 (2013). (d) Kitada, S., Takahashi, M., Yamaguchi, Y., Okada, Y., Chiba, K., Solublesupport-assisted electrochemical reactions: application to anodic disulfide bond formation. Org. Lett. 14, 5960-5963 (2012). (e) Tana, G., Kitada, S., Fujita, S., Okada, Y., Kim, S., Chiba, K., A practical solution-phase synthesis of an antagonistic peptide of TNF- $\alpha$ based on hydrophobic tag strategy. Chem. Commun. 46, 8219-8221 (2009).

(12) (a) Takahashi, D., Inomata, T., Fukui, T., AJIPHASEU®: A highly efficient synthetic method for one-pot peptide elongation in the solution phase by an Fmoc strategy. Angew. Chem., Int. Ed. 56, 7803-7807 (2017). (b) Aihara, K., Komiya, C., Shigenaga, A., Inokuma, T., Takahashi, D., Otaka, A., Liquid-phase synthesis of bridged peptides using olefin metathesis of a protected peptide with a long aliphatic chain anchor. Org. Lett. 17, 
696-699 (2015). (c) Takahashi, D., Yano, T., Fukui, T., Novel diphenylmethyl-derived amide protecting group for efficient liquid-phase peptide synthesis: AJIPHASE. Org. Lett. 14, 4514-4517 (2012). (d) Takahashi, D., Yamamoto, T., Development of an efficient liquid-phase peptide synthesis protocol using a novel fluorene-derived anchor support compound with Fmoc chemistry; AJIPHASE®. Tetrahedron Lett. 53, 1936-1939 (2012).

(13) (a) Seifert, C. W., Paniagua, A., White, G. A., Cai, L., Li, G., GAP peptide synthesis through the design of a GAP protecting group: An Fmoc/tBu synthesis of thymopentin free from polymers, chromatography and recrystallization. Eur. J. Org. Chem. 2016, 1714-1719 (2016). (b) Wu, J., An, G., Lin, S., Xie, J., Zhou, W., Sun, H., Pan, Y., Li, G., Solution-phase-peptide synthesis via the group-assisted purification (GAP) chemistry without using chromatography and recrystallization. Chem. Commun. 50, 1259-1261 (2014). (c) An, G., Seifert, C., Li, G., N-Phosphonyl/ phosphinyl imines and groupassisted purification (GAP) chemistry/technology. Org. Biomol. Chem. 13, 1600-1617 (2015).

(14) (a) Li, H. D., Chao, J., Tian, G., Hasan, J., Jin, Y. T., Zhang, Z. X., Qin, C. G., Resin-free peptide synthesis mediated by tri(4-benzoyl phenyl) phosphate (TBP) derivatives as small-molecule supports. Org. Chem. Front. 7, 689-696 (2020). (b) Li, H. D., Chao, J., Zhang, Z. X., Tian, G., Li, J., Chang, N. H., Qin, C. G., Liquid-phase total synthesis of plecanatide aided by diphenylphosphinyloxyl diphenyl ketone (DDK) derivatives. Org. Lett. 22, 3323-3328 (2020). (c) Li, H. D., Chao, J., Hasan, J., Tian, G., Jin, Y. T., Zhang, Z. X., Qin, C. G., Synthesis of tri(4-formylphenyl) phosphonate derivatives as recyclable triple-equivalent supports of peptide synthesis. J. Org. Chem. 85, 6271-6280 (2020). 
(15) (a) Pillaiyar, T., Manickam, M., Namasivayam, V., Hayashi, Y., Jung, S. H., An overview of severe acute respiratory syndrome-coronavirus (SARS-CoV) 3CL protease inhibitors: peptidomimetics and small molecule chemotherapy. J. Med. Chem. 59, 6595-6628 (2016). (b) Xue, X. Y., Yu, H. W., Yang, H. T., Xue, F., Wu, Z. X., Shen, W., Li, J., Zhou, Z., Ding, Y., Zhao, Q., Zhang, X .J. C., Liao, M., Bartlam, M., Rao, Z. H., Structures of two coronavirus main proteases: implications for substrate binding and antiviral drug design. J. Virol. 82, 2515-2527 (2008).

(16) (a) Jin, Z. M., Du, X. Y., Xu, Y. C., Deng, Y. Q., Liu, M. Q., Zhao, Y., Zhang, B., Li, X. F., Zhang, L. K., Peng, C., Duan, Y. K., Yu, J., Wang, L., Yang, K. L., Liu, F. J., Jiang, R. D., Yang, X. L., You, T., Liu, X. C., Yang, X. N., Bai, F., Liu, H., Liu, X., Guddat, L. W., Xu, W. Q., Xiao, G. F., Qin, C. F., Shi, Z. L., Jiang H. L., Rao, Z. H., Yang, H. T., Structure of Mpro from SARS-CoV-2 and discovery of its inhibitors. Nature. 582, 289-293 (2020). (b) Gil, C.; Ginex, T.; Maestro, I.; Nozal, V.; Barrado-Gil, L.; Cuesta-Geijo, M. A.; Urquiza, J.; Ramírez, D.; Alonso, C.; Campillo, N. E.; Martínez, A., COVID-19: Drug targets and potential treatments. J. Med. Chem. 2020, 10.1021/acs.jmedchem.0c00606.

(17) (a) Chou, K. C., Wei, D. Q., Zhong, W. Z., Binding mechanism of coronavirus main proteinase with ligands and its implication to drug design against SARS. Biochem. Biophys. Res. Commun. 308, 148-151 (2003). (b) Gan, Y. R., Huang, H., Huang, Y. D., Rao, C. M., Zhao, Y., Liu, J. S., Wu, L., Wei. D. Q., Synthesis and activity of an octapeptide inhibitor designed for SARS coronavirus main proteinase. Peptides. 27, $622-625$ (2006).

(18) Ren, J., Cao, G., Zhang, R. J., Li, D. W., Wei, T. T., Qin, C. G., Study on synthesis and 
activity of ACE inhibitory peptide. Acta. Pharm.Sinica. 46, 58-63 (2011).

(19) Li, G. H., Le, G. W., Shi, Y. H., Shrestha, S., Angiotensin I-converting enzyme inhibitory peptides derived from food proteins and their physiological and pharmacological effects. Nutr. Res. 24, 469-486 (2004).

(20) Jiang, Z. M., Wu, G., Liu, L. B., Tian, B., Huo, G. C., Study on stablization and inhibitory mechanism of antihypertensive peptide derived from bovine casein. Food Sci. 29, 249252 (2008).

(21) Yan, R. H., Zhang, Y. Y., Li, Y. N., Xia, L., Guo, Y. Y., Zhou, Q., Structural basis for the recognition of SARS-CoV-2 by full-length human ACE2. Science. 367, 1444-1448 (2020).

(22) (a) Lan, J., Ge, J. W., Yu, J. F., Shan, S. S., Zhou, H., Fan, S. L., Zhang, Q., Shi, X. L., Wang, Q. S., Zhang, L. Q., Wang, X. Q., Structure of the SARS-CoV-2 spike receptorbinding domain bound to the ACE2 receptor. Natuer. 581, 215-220 (2020). (b) Shang, J., Ye, G., Shi, K., Wan,Y. S., Luo, C. M., Aihara, H., Geng, Q. B., Auerbach, A., Li, F. Structural basis of receptor recognition by SARS-CoV-2. Nature. 581, 221-224 (2020).

(23) (a) Smith, J. C., Sausville, E. L., Girish, V., Yuan, M. L., Vasudevan, A., John, K. M., Sheltzer, J. M., Cigarette smoke exposure and inflammatory signaling increase the expression of the SARS-CoV-2 receptor ACE2 in the respiratory tract. Dev. Cell, 53, 514529 (2020). (b) Towler, P., Staker, B., Prasad, S. G., Menon, S., Tang, J., Parsons, T., Ryan, D., Fisher, M., Williams, D., Dales, N. A., Patane, M. A., Pantoliano, M. W., ACE2 X-ray structures reveal a large hinge-bending motion important for inhibitor binding and catalysis. J. Biol. Chem. 279, 17996-18007 (2004). (c) Li, W., Moore, M. J., Vasilieva, N. 
et al., Angiotensin-converting enzyme 2 is a functional receptor for the SARS coronavirus. Nature. 426, 450-454 (2003). (d) Hamming, I., Timens, W., Bulthuis, MLC., Lely, AT., Navis, G. J., Goor, H van., Tissue distribution of ACE2 protein, the functional receptor for SARS coronavirus. A first step in understanding SARS pathogenesis. J. Pathol. 203, $631-637$ (2004).

(24) Ho, T. Y., Wu, S. L., Chen, J. C. et al., Design and biological activities of novel inhibitory peptides for SARS-CoV spike protein and angiotensin-converting enzyme 2 interaction. Antivir. Res. 69, 70-76 (2006).

(25) (a) Natesh, R., Schwager, S. L. U., Sturrock, E. D., Acharya, K. R., Crystal structure of the human angiotensin-converting enzyme-lisinopril complex. Nature. 421, 551-554 (2003). (b) Wu, Q. Y., Jia, J. Q., Yan, H., Du, J. J., Gui, Z. Z., A novel angiotensin-I converting enzyme (ACE) inhibitory peptide from gastrointestinal protease hydrolysate of silkworm pupa (Bombyx mori) protein: Biochemical characterization and molecular docking study. Peptides. 68, 17-24 (2015). (c) Liu, L., Wei,Y. A., Chang, Q., Sun, H. J., Chai, K. G., Huang, Z. Q., Zhao, Z. X., Zhao Z. X., Ultrafast screening of a novel, moderately hydrophilic angiotensin converting-enzyme-inhibitory peptide, RYL, from silkworm pupa using an Fe-doped-silkworm-excrement-derived biocarbon: waste conversion by waste. J. Agric. Food. Chem. 65, 11202-11211 (2017). 


\section{Just For Graphical Abstract Only:}
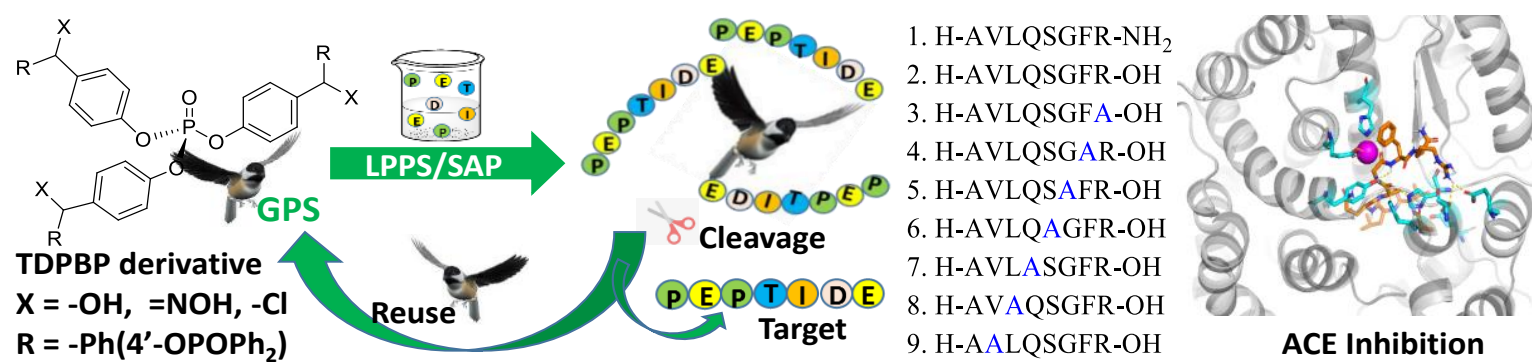